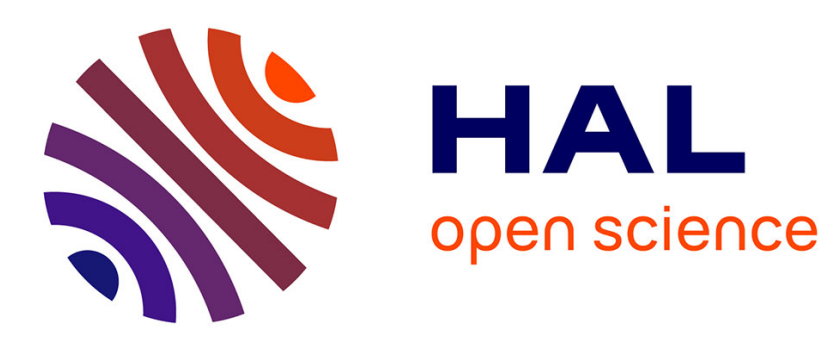

\title{
Temporal changes in the spatial pattern of leaf traits in a Quercus robur population
}

\author{
Covelo, Jose Ávila, Gallardo
}

\section{To cite this version:}

Covelo, Jose Ávila, Gallardo. Temporal changes in the spatial pattern of leaf traits in a Quercus robur population. Annals of Forest Science, 2011, 68 (3), pp.453-460. 10.1007/s13595-011-0054-6 . hal-00930789

\section{HAL Id: hal-00930789 \\ https://hal.science/hal-00930789}

Submitted on 1 Jan 2011

HAL is a multi-disciplinary open access archive for the deposit and dissemination of scientific research documents, whether they are published or not. The documents may come from teaching and research institutions in France or abroad, or from public or private research centers.
L'archive ouverte pluridisciplinaire HAL, est destinée au dépôt et à la diffusion de documents scientifiques de niveau recherche, publiés ou non, émanant des établissements d'enseignement et de recherche français ou étrangers, des laboratoires publics ou privés. 


\title{
Temporal changes in the spatial pattern of leaf traits in a Quercus robur population
}

\author{
Felisa Covelo • Jose Manuel Ávila • Antonio Gallardo
}

Received: 5 May 2010 /Accepted: 24 October 2010 /Published online: 7 April 2011

(C) INRA and Springer Science+Business Media B.V. 2011

\begin{abstract}
- Background Plant resources in natural ecosystems are frequently spatially structured at a scale relevant to individuals. This spatial structure can be variable in time, and can even vary within a single growing season. Several leaf traits may show spatial structure at the same scale as light or soil resources. However, whether this spatial structure stays constant from one growing season to the next is still unknown.

- Methods We hypothesize that the spatial structure of the limiting nutrient should be more stable over the years than the non-limiting nutrient. We also hypothesized that single leaf traits [leaf $\mathrm{N}$, leaf $\mathrm{P}$, and leaf mass per area ratio (LMA)] should be less spatially variable than those regulated by complex processes, such as leaf polyphenols or nutrient resorption efficiencies. We studied these different leaf traits in green and senesced young oak leaves sampled during 2000 and 2006, using a spatially explicit design.

- Results Leaf P, the most limiting nutrient, also showed the most stable spatial structure. Nitrogen and $\mathrm{P}$ resorption efficiencies had more variability than green leaf $\mathrm{N}$ and $\mathrm{P}$ respectively. Leaf polyphenols had the highest spatial and temporal variability of all studied leaf traits.
\end{abstract}

\footnotetext{
Handling Editor: Erwin Dreyer

F. Covelo · J. M. Ávila • A. Gallardo

Department of Physical, Chemical and Natural Systems, Pablo de Olavide University,

41013 Seville, Spain

F. Covelo $(\varangle)$

Departamento de Sistemas Físicos, Químicos y Naturales, Universidad Pablo de Olavide,

41013 Sevilla, Spain

e-mail: fcovnun@upo.es
}

- Conclusions Our results suggested that the variability of a leaf trait may increase as more variables control it. The relatively constant patch size makes the space predictable, and this may have important consequences for ecosystem processes such as litter decomposition and nutrient cycling.

Keywords Quercus robur . Leaf nitrogen . Leaf phosphorus - LMA · Total leaf polyphenols . Geostatistics $\cdot$ Nutrient resorption

\section{Introduction}

Spatial heterogeneity of essential resources for plants at different scales is a ubiquitous feature of natural ecosystems (Schlesinger et al. 1996; Gallardo 2003; Gallardo et al. 2006). The spatial distribution of essential resources has functional implications for plants, where they directly influence plant establishment and performance and affect populations, community, and ecosystem processes (Beckage and Clark 2003; Hutchings et al. 2003).

Previous studies have shown that the spatial pattern of soil resources at the scale of individual plants changes with successional status and disturbance (Robertson et al. 1993; Gross et al. 1995; Guo et al. 2004; Mou et al. 2005; Rodríguez et al. 2009). Furthermore, these soil spatial patterns change at shorter time scales, such as within a single growing season, and in different ways for different soil variables (Wang et al. 2007). These changes cause the correlation between soil resources and vegetation patterns to be weaker than predicted by theory (Ryel et al. 1996; Cain et al. 1999). Thus, sporadic soil sampling may not be an effective method to infer the effect of spatial variability 
of soil resources on plant nutrition. Additionally, plant roots preferentially exploit rich soil patches (Hodge 2004; Wang et al. 2006), raising serious questions about the net effect of soil resource variability on local performance of plants. However, Robertson et al. (1997), Covelo and Gallardo (2004), Gallardo and Covelo (2005), and Covelo et al. (2008a) found a spatial structure in leaf traits at a scale similar to soil resources. This similarity suggests that even if soil heterogeneity is changing with time, these changes have a net effect on plants, and that the plants experience a heterogeneous environment. Little is known about the temporal changes in the spatial patterns of leaf traits, although it is known that spatial patterns change along leaf senescence (Covelo et al. 2008a).

The main objective of this study was to evaluate whether the spatial pattern of leaf traits was maintained at a scale of years. We chose Quercus robur (pedunculate oak) young trees because they represent the dominant tree species in the deciduous forest of NW Spain. We compared the global variability $(\mathrm{CV})$ and the spatial structure of several oak leaf traits [eaf $\mathrm{N}$, leaf $\mathrm{P}$, leaf mass-to-area ratio (LMA) and leaf polyphenols] in the same forest stand in 2000 and 2006. We selected these variables because $\mathrm{N}$ and $\mathrm{P}$ are the two most important nutrients for plants, LMA is correlated with light availability, and leaf polyphenols represent investment of excess carbon compounds for leaf protection and defence (Jones and Hartley 1999; Poorter et al. 2009). Based on the fact that plant uptake will tightly depend on soil nutrient availability, and the capacity of plants to increase their potential for absorbing the limiting nutrient and reducing the absorption of other ions (e.g., Lee 1982), we hypothesised that the leaf concentration of the most limiting nutrient would be more variable than nonlimiting nutrients over time. In addition, the spatial structure of the limiting nutrient should be more stable over the years than the non-limiting nutrient insofar as the limitation remains. Numerous variables affect leaf traits. For example, in addition to soil availability, leaf $\mathrm{N}$ or leaf $\mathrm{P}$ are influenced by factors like light availability, herbivory, and ontogenetic stage. The same can be said for leaf polyphenols; however, the synthesis of these compounds further depends on resource allocation to secondary metabolism. Based on this reasoning, we hypothesized that single leaf traits such as green leaf $\mathrm{N}$, leaf $\mathrm{P}$, and LMA should be less globally variable than complex regulated substances, such as leaf polyphenols, less variable than their senescent counterparts, and less variable than compound indexes such as nutrient resorption efficiencies. As most factors influencing these leaf traits showed spatial dependence (Covelo and Gallardo 2004; Gallardo and Covelo 2005 and Covelo et al. 2008a), we also extended our hypothesis to the spatial variability of those traits.

\section{Materials and methods}

\subsection{Study site}

The study was conducted in a 30-year-old maritime pine forest (Pinus pinaster Aiton) in northwestern Spain $\left(42^{\circ} 10^{\prime} \mathrm{N}\right.$, $08^{\circ} 40^{\prime} \mathrm{W}$ ). The site was located $450 \mathrm{~m}$ above sea level near the University of Vigo. The density of pine trees was approximately 400 trees per hectare, with an average height of $15 \mathrm{~m}$. Leaf area index and canopy openness (as estimated by hemispherical photograph) ranged from 1.67 to 2.15 and $17.1 \%$ to $19.5 \%$ respectively. The stratum under the pine canopy largely comprised young (approximately 10 - to 15 year-old) deciduous oaks (Quercus robur L.), with the occasional presence of Castanea sativa Mill. The herbaceous stratum was dominated by Bracken fern (Pteridium aquilinum (L.) Kuhn) and Agrostis curtisii Kerguelen. The climate is warm-temperate with a slight Mediterranean influence, with little rainfall during the summer months. Mean annual rainfall is about $1,800 \mathrm{~mm}$, and the mean annual temperature is about $15^{\circ} \mathrm{C}$. Soils (classified as Humic Cambisol) are acidic ( $\mathrm{pH} 4.3-4.7)$ and derived from the weathering of gneiss bedrock (IGME 1981). These sandy soils are characterized by high organic carbon and total nitrogen content (111 and $7.6 \mathrm{mg} \mathrm{g}^{-1}$ respectively), and very low concentrations of other nutrients, especially available phosphorus $\left(2.8 \mathrm{mg} \mathrm{kg}^{-1}\right)$.

\subsection{Field sampling}

An area of approximately $120 \times 120 \mathrm{~m}$ was chosen from within the study site. An irregular plot was marked inside this area, where apparently disturbed surfaces (affected by roadways or forestry works) with a buffer (approximately $10 \mathrm{~m})$ were excluded. All young oak trees in the plot $(n=$ 125 ) were tagged and mapped using the computer program INTERPN, which is based on tree diameter and tree-to-tree distance measurements (Boose et al. 1998). Mean and minimum distances between trees were $4.4 \mathrm{~m}$ and $1.1 \mathrm{~m}$. Oak leaves were sampled in 2000 and 2006 during August (green leaves) and December (senesced leaves), and the same methods were applied for both sampling years. We chose this time interval to be long enough to avoid temporal autocorrelation, but short enough to minimize changes in the oak stand development. About 20-25 leaves from different positions were picked from each tree. Senesced leaves were sampled after abscission, just prior to leaf fall (leaves would fall from the tree with just a gentle shake or touch). Leaves were collected directly from trees rather than from the leaf litter, to ensure sampling of fresh abscised leaves and to avoid soil contamination. Leaves were transported to the laboratory in a cooler under dark conditions, and processed within $24 \mathrm{~h}$. 


\subsection{Laboratory analysis}

To calculate leaf mass-to-area ratio (LMA), air-dried leaves from each tree were individually weighed and their areas were calculated using the UTHSCSA Image Tool 2.0 software (ftp://maxrad6.uthscsa.edu). Leaf samples were finely ground (passed through a $0.5 \mathrm{~mm}$ screen) without heating. For leaf $\mathrm{N}$ and $\mathrm{P}$ analysis, leaf samples were digested in selenous sulphuric acid (Walinga et al. 1995). Three replicate samples of diluted aliquots of the digestion were analysed by colourimetry for $\mathrm{N}$ (indophenol blue method) and for P (molybdenum blue method) using a microplate reader (Sims et al. 1995). Total leaf phenolics concentration was determined following the method of Makkar (2003). Duplicate extraction of $0.2 \mathrm{~g}$ of leaf tissue with $10 \mathrm{ml}$ of $70 \%$ aqueous acetone $(\mathrm{v} / \mathrm{v})$ was performed by using ultrasonic treatment in a water bath (Branson 3210) for $20 \mathrm{~min}$ at room temperature. The extracts were centrifuged for $10 \mathrm{~min}$ at $3,000 \mathrm{~g}$ at $4^{\circ} \mathrm{C}$, and total polyphenol content in the supernatant was measured colourimetrically using the Folin-Ciocalteu reagent, with tannic acid from Merck as a standard (Makkar 2003). Total leaf polyphenol concentration was expressed in tannic acid equivalents (TAE) as $\mathrm{mg} \mathrm{g}^{-1}$ of leaf dry weight.

\subsection{Resorption efficiency}

Leaf nitrogen and phosphorus resorption efficiency (defined as the percent of reabsorbed nutrients relative to the maximum amount of that nutrient in green leaves) was calculated on a leaf surface basis to avoid any effect of changes in leaf weight during senescence (Aerts 1996).

\subsection{Statistical analysis}

Spatial dependence of the samples was analysed using geostatistical analyses (Rossi et al. 1992). For each variable, semivariograms were used to analyse the autocorrelation at increasing distances. To estimate the magnitude of spatial dependence, we calculated the percentage of total variance $\left(\right.$ sill; $\left.\mathrm{C}_{0}+\mathrm{C}\right)$ explained by the structural variance (C, variance explained by spatial autocorrelation). To estimate the scale at which dependence occurs, we estimated the distance beyond which samples are independent (range). Prior to performing the semivariogram, the soil properties were log-transfomed when the Shapiro-Wilk test indicated lack of normality. When this transformation failed, we used a Box-Cox transformation (Box and Cox 1964; Ribeiro and Diggle 2001). Detrended analysis and the corresponding semivariograms for the residuals were performed for each variable. To facilitate comparisons, all the empirical semivariograms were fitted to a spherical model. The model fitted to the semivariogram allows for interpolation ('kriging'), which provides optimal, unbiased estimates of non-sampled points. Although the resulting maps provide a powerful visualization of pattern (Ettema and Wardle 2002), we opted for maps showing the probability of exceeding a threshold value (we chose the mean value). The probabilities were calculated by performing 1,000 conditional simulations on the predicted distribution of values. These stochastic models have the advantages (1) of avoiding the smoothing effect of any interpolation method, and (2) of including a measure of uncertainty in the maps (Chilès and Delfiner 1999).

The relationships and differences between spatially distributed data cannot be analysed using classical statistical tests, such as ordinary least squares (OLS) regression or analysis of variance, because the assumption of independently distributed errors is often invalid. To include the effects of spatial autocorrelation, the differences in leaf traits between years were tested using a spatially adjusted one-way ANOVA (Griffith 1978). We used conditional autoregressive models (CAR, Lichstein et al. 2002) to evaluate the relationship between leaf traits in 2000 and 2006. Statistical and geostatistical analysis were performed with R 2.7 statistical software (Ellner 2001; R Development Core Team 2008) using the geostatistical modules geoR and gstat (Ribeiro and Diggle 2001).

\section{Results}

Global variability (as measured by the $\mathrm{CV}$ ) ranged from $9.8 \%$ to $38.4 \%$, with the lowest variability in the leaf massto-area ratio (LMA) and the highest variability in the total leaf polyphenols (TLP) concentrations in both green and senescent leaves and for the 2 sampling years (Table 1). The global variability of leaf $\mathrm{N}$ was less than the variability of leaf $\mathrm{P}$, and $\mathrm{N}$ and $\mathrm{P}$ resorption efficiencies (NRE and PRE) had higher CVs than single leaf traits in green leaves. Leaf traits in senesced leaves had higher global variability than in green leaves, while for most leaf traits the CVs in 2000 were markedly similar to those in 2006.

We found significant correlations between the 2 sampling years for LMA, leaf $\mathrm{N}$, leaf $\mathrm{P}, \mathrm{N}$-to $\mathrm{P}$ ratio and PRE (Table 2). Higher correlations were observed for green leaves than for senesced leaves (Table 2). The correlation between leaf $\mathrm{P}$ in 2000 and 2006 had the highest percent of explained variance $\left(R^{2}=0.45, P<0.001\right)$. Leaf $\mathrm{N}$ levels in 2000 and 2006 were the least correlated $\left(R^{2}=0.037, P<0.05\right)$.

All semivariograms were significantly fitted to a spherical model, indicating the existence of spatial dependence for all studied variables and for both years $(P<0.05$, Table 3$)$. The percentage of total variance explained by spatial dependence $\left(\mathrm{C} /\left[\mathrm{C}_{0}+\mathrm{C}\right]\right)$ ranged between $31.2 \%$ and 
Table 1 Mean and coefficient of variation for the analysed variables in green and senesced oak leaves $(n=125)$ in 2000 and 2006. LMA, leaf $\mathrm{N}$ and TLP for the year 2000 sampling were re-analysed from Covelo and Gallardo (2004), green leaf P from Gallardo and Covelo (2005), and NRE and PRE from Covelo et al. (2008a). LMA, leaf N and TLP for the year 2006 sampling were re-analysed from Covelo and Gallardo (2009)

\begin{tabular}{|c|c|c|c|c|c|c|}
\hline & \multicolumn{2}{|c|}{ Green leaf } & \multirow[t]{2}{*}{$P$} & \multicolumn{2}{|c|}{ Senesced leaf } & \multirow[t]{2}{*}{$P$} \\
\hline & 2000 & 2006 & & 2000 & 2006 & \\
\hline \multicolumn{7}{|c|}{ LMA $\left(\mathrm{mg} \mathrm{cm}^{-2}\right)$} \\
\hline Mean & 6.2 & 6.6 & \multirow[t]{2}{*}{0.001} & 5.9 & 5.8 & \multirow[t]{2}{*}{ n.s. } \\
\hline C.V. & 10.4 & 11.6 & & 12.6 & 11.4 & \\
\hline \multicolumn{7}{|c|}{$\mathrm{N}\left(\mathrm{mg} \mathrm{g}^{-1}\right)$} \\
\hline Mean & 21.5 & 22.2 & \multirow[t]{2}{*}{ n.s. } & 15.7 & 13.8 & \multirow[t]{2}{*}{0.001} \\
\hline C.V. & 9.8 & 11.4 & & 17.2 & 15.1 & \\
\hline \multicolumn{7}{|c|}{$\mathrm{P}\left(\mathrm{mg} \mathrm{g}^{-1}\right)$} \\
\hline Mean & 1.29 & 1.24 & \multirow[t]{2}{*}{ n.s. } & 0.73 & 0.75 & \multirow[t]{2}{*}{ n.s. } \\
\hline C.V. & 21.0 & 20.9 & & 34.2 & 34.8 & \\
\hline \multicolumn{7}{|l|}{$\mathrm{N}$ to $\mathrm{P}$} \\
\hline Mean & 17.3 & 18.6 & \multirow[t]{2}{*}{ n.s. } & 21.0 & 19.4 & \multirow[t]{2}{*}{0.01} \\
\hline C.V. & 18.3 & 21.6 & & 26.6 & 33.7 & \\
\hline \multicolumn{7}{|c|}{ TLP $\left(\mathrm{mg} \mathrm{g}^{-1}\right)$} \\
\hline Mean & 141.7 & 119.2 & \multirow[t]{2}{*}{0.001} & 89.1 & 88.4 & \multirow[t]{2}{*}{ n.s. } \\
\hline C.V. & 27.0 & 24.6 & & 38.4 & 35.0 & \\
\hline \multicolumn{7}{|c|}{ NRE (\%) } \\
\hline Mean & 33.4 & 44.7 & \multirow[t]{2}{*}{0.001} & & & \\
\hline C.V. & 36.5 & 23.4 & & & & \\
\hline \multicolumn{7}{|c|}{ PRE (\%) } \\
\hline Mean & 48.0 & 46.4 & \multirow[t]{2}{*}{ n.s. } & & & \\
\hline C.V. & 37.2 & 34.1 & & & & \\
\hline
\end{tabular}

NS: $P>0.05 . \mathrm{TLP}=$ total leaf polyphenols; $\mathrm{NRE}$ and $\mathrm{PRE}=$ nitrogen and phosphorus resorption efficiency, respectively

Table 2 Conditional autoregressive models (CAR) between analysed variables in green and senesced oak leaves in 2000 and in 2006. $N=125$

\begin{tabular}{lllll}
\hline Green leaves & & & \multicolumn{2}{l}{ Senesced leaves } \\
\cline { 5 - 6 } \cline { 5 - 5 } 2006 vs 2000 & $R$ & & 2006 vs 2000 & $R$ \\
\hline LMA & $0.42^{* * *}$ & & LMA & $0.3^{* *}$ \\
$\mathrm{~N}$ & $0.19^{*}$ & & $\mathrm{~N}$ & $0.25^{*}$ \\
$\mathrm{P}$ & $0.67^{* * *}$ & & $\mathrm{P}$ & $0.22^{*}$ \\
$\mathrm{~N}: \mathrm{P}$ & $0.61^{* * *}$ & & $\mathrm{~N}: \mathrm{P}$ & $0.23^{*}$ \\
TLP & n.s. & & TLP & n.s. \\
NRE & n.s. & & \\
PRE & $0.2^{*}$ & & \\
\hline
\end{tabular}

A single asterisk (*) indicates $P<0.05$; double asterisks (**) indicates $P<0.01$; triple asterisks $(* * *)$ indicates $P<0.001$; n.s. indicates $P>$ 0.05 . Only the non-spatial component of the model is shown. $\mathrm{TLP}=$ total leaf polyphenols; NRE and $\mathrm{PRE}=$ nitrogen and phosphorus resorption efficiency, respectively
Table 3 Variogram model parameters for leaf variables in green and senescent oak leaves in 2000 and 2006. $N=125$. Semivariograms were adjusted significantly $(P<0.05)$ to a spherical model. LMA, leaf $\mathrm{N}$ and TLP for the year 2000 sampling were re-analysed from Covelo and Gallardo (2004), green leaf P from Gallardo and Covelo (2005), and NRE and PRE from Covelo et al. (2008a). LMA, leaf N and TLP for the 2006-yr sampling were re-analysed from Covelo and Gallardo (2009)

\begin{tabular}{|c|c|c|c|c|c|c|}
\hline \multirow[t]{2}{*}{ Green leaf } & \multicolumn{3}{|l|}{2000} & \multicolumn{3}{|l|}{2006} \\
\hline & $\begin{array}{l}\text { Range } \\
(\mathrm{m})\end{array}$ & $\begin{array}{l}\text { Structural } \\
\text { variance } \\
\mathrm{C} /\left(\mathrm{C}_{0}+\mathrm{C}\right) \\
(\%)\end{array}$ & $R^{2}$ & $\begin{array}{l}\text { Range } \\
(\mathrm{m})\end{array}$ & $\begin{array}{l}\text { Structural } \\
\text { variance } \\
\mathrm{C} /\left(\mathrm{C}_{0}+\mathrm{C}\right) \\
(\%)\end{array}$ & $R^{2}$ \\
\hline $\begin{array}{l}\text { LMA } \\
\qquad\left(\mathrm{mg} \mathrm{cm}^{-2}\right)\end{array}$ & 6.0 & 43.2 & 0.451 & 9.0 & 37.1 & 0.851 \\
\hline $\mathrm{N}\left(\mathrm{mg} \mathrm{g}^{-1}\right)$ & 10.5 & 53.1 & 0.761 & 10.5 & 77.1 & 0.875 \\
\hline $\mathrm{P}\left(\mathrm{mg} \mathrm{g}^{-1}\right)$ & 12.0 & 77.4 & 0.899 & 10.0 & 35.9 & 0.621 \\
\hline $\mathrm{N}$ to $\mathrm{P}$ ratio & 13.0 & 80.4 & 0.916 & 13.0 & 48.2 & 0.791 \\
\hline TLP ( $\left.\mathrm{mg} \mathrm{g}^{-1}\right)$ & 16.4 & 74.7 & 0.934 & 9.34 & 39.8 & 0.725 \\
\hline \multicolumn{7}{|l|}{ Senesced leaf } \\
\hline $\begin{array}{l}\mathrm{LMA} \\
\left(\mathrm{mg} \mathrm{cm}^{-2}\right)\end{array}$ & 13.0 & 49.1 & 0.880 & 8.0 & 100 & 0.860 \\
\hline $\mathrm{N}\left(\mathrm{mg} \mathrm{g}^{-1}\right)$ & 13.5 & 48.6 & 0.935 & 12.0 & 39.8 & 0.814 \\
\hline $\mathrm{P}\left(\mathrm{mg} \mathrm{g}^{-1}\right)$ & 21.0 & 51.8 & 0.938 & 12.4 & 100 & 0.953 \\
\hline $\mathrm{N}$ to $\mathrm{P}$ ratio & 10.0 & 82.0 & 0.821 & 16.0 & 69.9 & 0.913 \\
\hline TLP (mg g $\left.{ }^{-1}\right)$ & 19.0 & 31.2 & 0.735 & 7.3 & 79.5 & 0.909 \\
\hline \multicolumn{7}{|c|}{ Resorption efficiency } \\
\hline NRE $(\%)$ & 13.8 & 71.5 & 0.850 & 9.7 & 54.1 & 0.956 \\
\hline PRE (\%) & 15.0 & 82.4 & 0.876 & 15.6 & 100 & 0.909 \\
\hline
\end{tabular}

LMA $=$ Leaf mass to area ratio. TLP $=$ Total leaf polyphenols $\mathrm{NRE}=$ Nitrogen resorption efficiency. PRE $=$ Phosphorus resorption efficiency

$100 \%$ (Table 3). Some variables, such as the N-to-P ratio or TLP, showed considerable structural variance changes. In green leaves, the distance at which samples remained spatially correlated ranged from $6 \mathrm{~m}$ (LMA) to $16.4 \mathrm{~m}$ (TLP). LMA, leaf $\mathrm{N}$ and $\mathrm{P}$ concentrations, $\mathrm{N}$ to $\mathrm{P}$ ratio and PRE had similar ranges for the 2 sampling years. However, TLP and NRE had the highest differences in patch size between 2000 and 2006 (Table 3). In senesced leaves, the spatial ranges of leaf traits tended to be higher and more variable than in green leaves, varying between $7.3 \mathrm{~m}$ (TLP) and $21 \mathrm{~m}$ (leaf P). Differences in the range between the 2000 and 2006 sampling years were higher in senesced than in green leaf traits.

\section{Discussion}

Fraterrigo and Rusak (2008) suggested that variability can be an extremely sensitive metric for studying processes that structure ecosystems, and that variability may capture 
differences obscured by averaging, and thereby reveal important ecological information about underlying causal processes. We found that the coefficient of variation was remarkably similar for most leaf traits in 2000 and 2006, even for those leaf traits that had significant differences in the mean values of those years. Thus, global variability may be a fixed ecosystem property at the temporal scale examined, at least in undisturbed plant communities (Collins 2000). The similar CVs probably indicate the maximum and minimum physiological levels of those leaf traits in the oak population. Interestingly, the structural variance showed considerable changes for some variables (such as the N-to-P ratio or the TLP), suggesting that even under the same variability limits marked by the CVs, the importance of the spatial and non-spatial components of the variance may experience significant changes. However, a clear pattern of these changes did not emerge from our results. The spatial ranges for most of the leaf properties (excepting TLP) were also fairly similar between 2000 and 2006, at least in green leaves, suggesting that it may also be an intrinsic property of this ecosystem.

A 6-year period is a relatively short time span compared to the evolution in an oak stand to expect major changes in soil fertility and leaf nutrient content. However, even if overall nutrient content did not change, a high temporal variability at shorter time scale (even within a single growing season) in the spatial structure of soil nutrient have been described (Ryel et al. 1996; Cain et al. 1999; Guo et al. 2004). Therefore, we initially expected a low coincidence in the spatial pattern of leaf nutrient content between 2000 and 2006. Nevertheless, the opposite results for green leaves were found, suggesting that even if the spatial properties of soil resources change temporally, plants perceive that spatial heterogeneity at a fixed spatial scale.

In senescent leaf traits, the spatial ranges varied by a factor of two to three between 2000 and 2006. This high inter-annual variability may be a result of the physiological processes involved in leaf senescence being concentrated in a short period of the year. Then, senescent leaf traits may be more dependent on short-term climatic variability and the physiological status of the trees. The range is an important spatial property that defines patch size, and although it was similar in both years for several leaf traits, the patches in those years may not be the same. For example, we detected a high spatial coincidence between patches of high and low levels of leaf P between 2000 and 2006 (Fig. 1), but the spatial correlation was much lower for leaf $\mathrm{N}$, despite the fact that the spatial ranges were very similar for both sampling years. Phosphorus is probably the most limiting nutrient in this ecosystem (Gallardo and Covelo 2005; Covelo et al. 2008b), supporting our hypothesis that the spatial variability of a limiting nutrient should be higher but also more temporally stable than a non-limiting nutrient (such as N). The spatial structure of $\mathrm{P}$ would be coupled with soil $\mathrm{P}$ availability, and insofar as a group of nearby trees find low or high soil $\mathrm{P}$ availability, this pattern would be reflected in the leaf chemistry in different years. In contrast to leaf $\mathrm{P}$, leaf $\mathrm{N}$ concentration would be uncoupled with soil $\mathrm{N}$ availability because it is relatively abundant in the soil, and consequently, leaf $\mathrm{N}$ global variability would be low. Then, the observed spatial structure in 2000 and 2006 would be caused by factors other than soil $\mathrm{N}$ availability (e.g., physiologic investment in structural or functional N compounds; Niinemets 1997). PRE was also significantly correlated between years, while NRE was not, confirming that differences between these two nutrients are reflected in the temporal stability of the spatial pattern.

LMA had the lowest global variability of all examined leaf traits, as predicted in our hypothesis. The variability of LMA should be related primarily to spatial variability in light availability, although it may also be influenced by other variables such as water or $\mathrm{N}$ availability (Poorter et al. 2009). Young oaks were growing under a regular and mature pine canopy with low spatial variability in total transmitted radiation (Covelo and Gallardo 2004). As suggested by Rich (1990), mature pine canopies typically have a relatively homogeneous physical structure, with low variability in space and time. This low temporal variability may explain why patch size for LMA was very similar in 2000 and 2006.

As opposed to LMA, total leaf polyphenols had the highest spatial and temporal variability of all studied leaf traits, and total leaf polyphenols was the only trait that had substantial changes in the spatial range of the variogram between 2000 and 2006 in both green and senescent leaves. This is consistent with our hypothesis, where the variability of a leaf trait should increase when more variables control it. Leaf polyphenol concentrations have been attributed to stress, harmful radiation, herbivores and the C-to- $\mathrm{N}$ balance (Koricheva et al. 1998; Jones and Hartley 1999). The variability of leaf polyphenols in the oak population is likely to depend on any combination of these factors, which in turn may also have spatial dependence (Brenes-Arguedas and Coley 2005; Andrew et al. 2007).

Global variability was higher in senescent leaves than in green leaves for all leaf variables, which is consistent with the findings of Covelo and Gallardo (2004) and Covelo et al. (2008a). Differences between CVs in 2000 and 2006 were also higher for senescent than green leaves. While green leaf nutrient concentrations may depend on nutrient availability, senescent leaf nutrient concentration is regulated by more complex metabolic processes, and therefore we predicted higher variability in the spatial structure of senescent leaves. However, as mentioned above, the temporal scale at which physiological processes occur 
Fig. 1 Semivariograms and kriged maps for the probability of finding a value higher than the mean $\mathrm{P}$ and $\mathrm{N}$ content in green leaves of Quercus robur in 2000 and 2006. The lines in the semivariograms represent the fitted spherical model

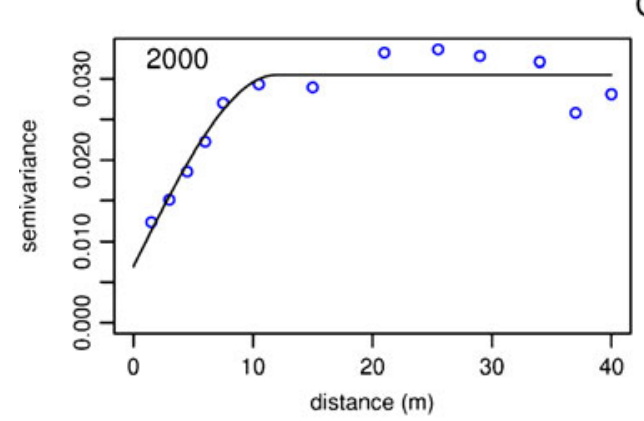

Green P
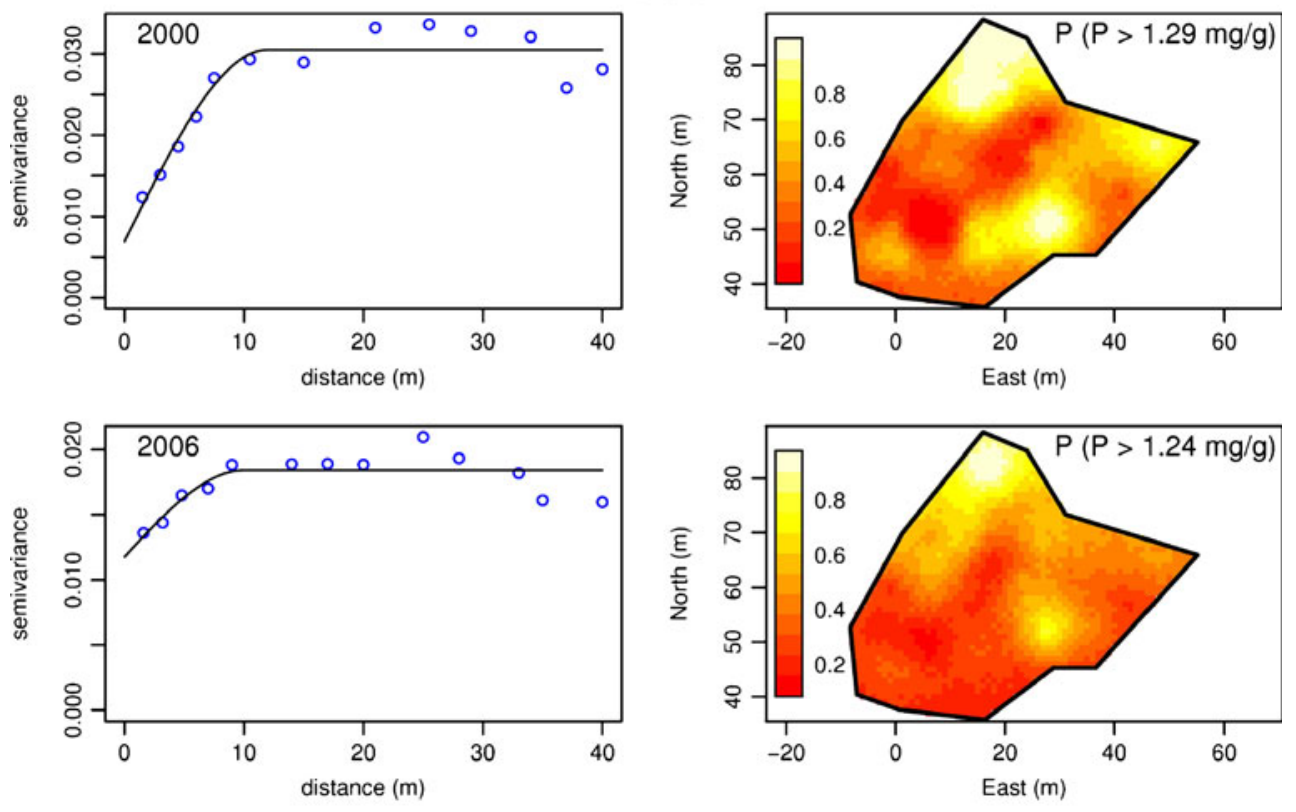

Green N
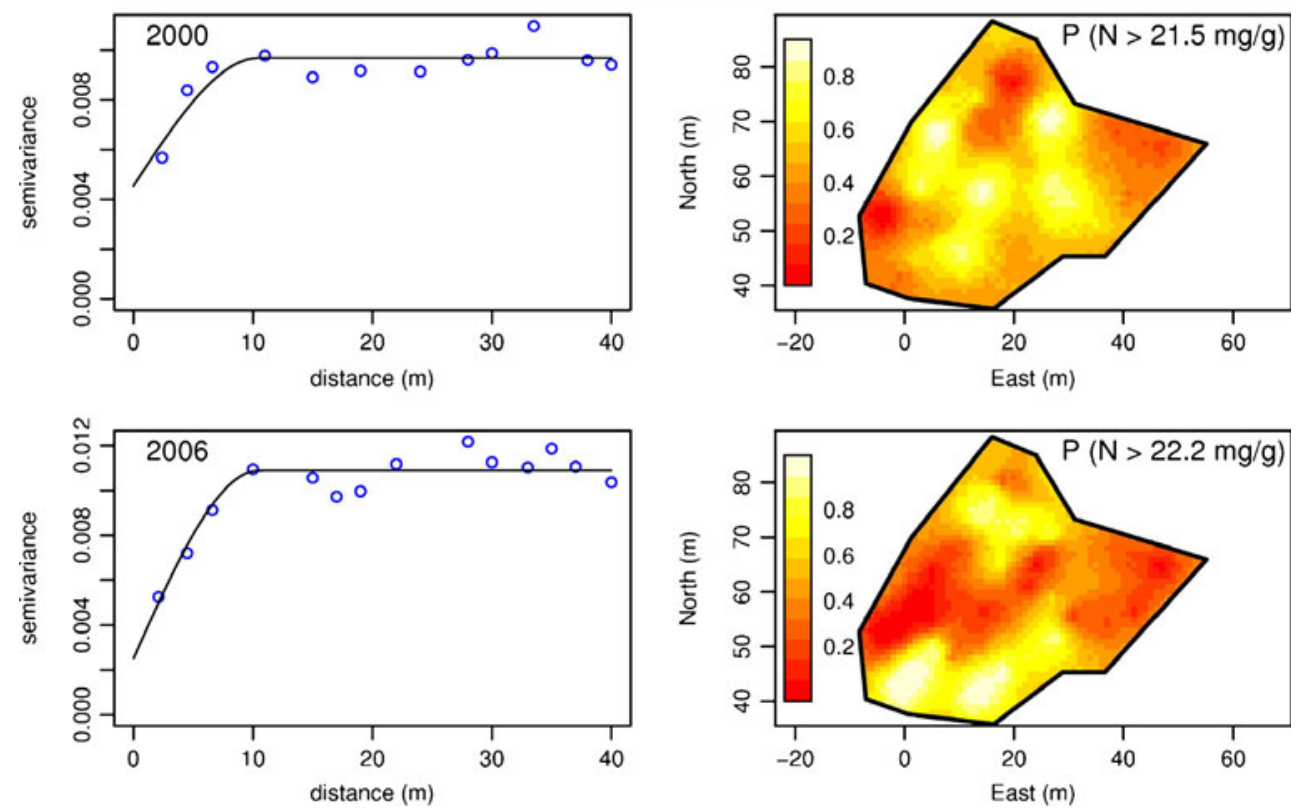

may also affect the variability of leaf traits. Green leaf nutrient content is the result of the entire growing season, but senescent leaf nutrient content is the result of relatively rapid changes during a short period of time (Thomas and Stoddart 1980). Differences in time scale may also explain why NRE and PRE had more variability than green leaf $\mathrm{N}$ and $\mathrm{P}$ respectively. A high variability in nutrient resorption efficiencies was noted by Nordell and Karlsson (1995), Killingbeck (1996) and Covelo et al. (2008b).

We attempted to explain differences in the variability between leaf traits based on responses to environmental resources or the time scale at which processes influencing those leaf traits occur. However, comparisons of variability among different leaf traits are not straightforward, because differences in leaf plasticity for the different compounds may also explain differences in the global variability and the spatial structure of these leaf traits. Genotypic similarity between nearby trees is another mechanism that can create spatial structure independently of environmental variation in plant resources. We do not know if trees separated by only a few meters are more genetically similar than trees several meters apart, but oak acorns are dispersed by birds and mammals, and accordingly, we do not expect genotypic variability to make a difference in a relatively small area. A similar idea is that leaf traits might keep constant between years for the same individuals, therefore showing a 
relatively stable spatial structure in the oak population. In this case, the variables for plant plastic responses would be the number of leaves more than individual leaf traits. However, leaf nutrient concentrations reflect both genotypic and phenotypic sources of variation, and nutrient availability may increase concentrations within species, especially when another nutrient becomes limiting (Aerts and Chapin 2000). We previously found in the same area a significant correlation and spatial dependence between leaf $\mathrm{P}$ concentration in oaks and indicators of $\mathrm{P}$ soil availability (Gallardo and Covelo 2005), suggesting phenotypic responses of oak leaves to environment resources.

To identify which mechanisms are responsible for the spatial structure of leaf traits and why patches of leaf traits varied with time is still challenging. Few papers have described the existence of spatial structure of leaf traits at a scale of meters to hundred of meters, and we are not aware of any paper describing changes in spatial structure with time at this scale. We demonstrated that one of the most important characteristics of spatial structure, patch size, was relatively constant for 6 years for most of the studied variables. Furthermore, some variables had a high spatial coincidence of patches of high or low leaf trait content during that time interval, demonstrating that the spatial structure found in deciduous tree species is not the effect of a single growing season. The likely changes in environmental variables and tree growth which occurred during the 6-year period make more remarkable the coincidence in the spatial pattern of some of our leaf traits. The spatial structure maintained across time makes the space predictable, and it may have important consequences for ecosystem processes such as herbivory or litter decomposition.

Acknowledgements This work was financed by the Ministerio de Educación y Ciencia of the Spanish Government (REN2003-08620-C0201; CGL 2006-13665-C02-01). We thank Daniel Caballero e Afra for their valuable help with the field and laboratory measurements.

\section{References}

Aerts R (1996) Nutrient resorption from senescing leaves of perennials: are there general patterns? J Ecol 84:597-608

Aerts R, Chapin FS III (2000) The mineral nutrition of wild plants revisited: a re-evaluation of processes and patterns. Adv Ecol Res 30:1-67

Andrew RL, Peakall R, Wallis IR, Foley WJ (2007) Spatial distribution of defense chemicals and markers and the maintenance of chemical variation. Ecology 88:716-728

Beckage B, Clark JS (2003) Seedling survival and growth of three forest tree species: the role of spatial heterogeneity. Ecology 84:1849-1861

Boose ER, Boose EF, Lezberg AL (1998) A practical method for mapping trees using distance measurements. Ecology 79:819-827

Box GEP, Cox DR (1964) An analysis of transformations. J R Stat Soc 26:211-243
Brenes-Arguedas T, Coley PD (2005) Phenotypic variation and spatial structure of secondary chemistry in a natural population of a tropical tree species. Oikos 108:410-420

Cain ML, Subler S, Evans JP, Fortin MJ (1999) Sampling spatial and temporal variation in soil nitrogen availability. Oecologia 118:397-404

Chilès J-P, Delfiner P (1999) Geostatistics. Modeling spatial uncertainty. Wiley-Interscience, New York

Collins SL (2000) Disturbance frequency and community stability in native tallgrass prairie. Am Nat 155:311-325

Covelo F, Gallardo A (2004) Green and senescent leaf phenolics showed spatial autocorrelation in a Quercus robur population in northwestern Spain. Plant Soil 259:267-276

Covelo F, Gallardo A (2009) Changes in the spatial structure of oak carbon-based secondary compounds after pine harvesting. For Ecol Manage 258:2511-2518

Covelo F, Rodriguez A, Gallardo A (2008a) Spatial pattern and scale of leaf $\mathrm{N}$ and $\mathrm{P}$ resorption efficiency and proficiency in a Quercus robur population. Plant Soil 311:109-119

Covelo F, Durán J, Gallardo A (2008b) Leaf resorption efficiency and proficiency in a Quercus robur population following forest harvest. For Ecol Manage 255:2264-2271

Ellner SP (2001) R version 1.1.1. Bull Ecol Soc Am 82:127-128

Ettema CH, Wardle DA (2002) Spatial soil ecology. Trends Ecol Evol 17:177-183

Fraterrigo JM, Rusak JA (2008) Disturbance-driven changes in the variability of ecological patterns and processes. Ecol Lett $11: 756-770$

Gallardo A (2003) Spatial variability of soil properties in a floodplain forest in northwestern Spain. Ecosystems 6:564-576

Gallardo A, Covelo F (2005) Spatial pattern and scale of leaf N and P concentration in a Quercus robur population. Plant Soil 273:269-277

Gallardo A, Paramá R, Covelo F (2006) Differences between soil ammonium and nitrate spatial pattern in six plant communities. Simulated effect on plant populations. Plant Soil 279:333-346

Griffith DA (1978) A spatially adjusted ANOVA model. Geogr Anal 10:296-301

Gross KL, Pregitzer KS, Burton AJ (1995) Spatial variation in nitrogen availability in three successional plant communities. J Ecol 83:357-367

Guo D, Mou P, Jones RH, Mitchell RJ (2004) Spatio-temporal patterns of soil available nutrients following experimental disturbance in a pine forest. Oecologia 138:613-621

Hodge A (2004) The plastic plant: root responses to heterogeneous supplies of nutrients. New Phytol 162:9-24

Hutchings MJ, John EA, Wijesinghe DK (2003) Toward understanding the consequences of soil heterogeneity for plant populations and communities. Ecology 84:2322-2334

IGME (1981) Mapa geológico de España. Ministerio de Industria y Energía. Madrid Spain

Jones CG, Hartley SE (1999) A protein competition model of phenolic allocation. Oikos 86:27-44

Killingbeck KT (1996) Nutrients in senesced leaves: keys to the search for potential resorption and resorption proficiency. Ecology 77:1716-1727

Koricheva J, Larsson S, Haukioja E, Keinänen M (1998) Regulation of woody plant secondary metabolism by resource availability: hypothesis testing by means of metanalysis. Oikos 83:212226

Lee RB (1982) Selectivity and kinetics of ion uptake by barley plant following nutrient deficiency. Ann Bot 50:429-449

Lichstein JW, Simons TR, Shriner SA, Franzreb KE (2002) Spatial autocorrelation and autoregressive models in ecology. Ecol Monogr 72:445-463

Makkar HPS (2003) Quantification of tannins in tree foliage. A laboratory manual. Kluwer, Dordrecht, p 102 
Mou P, Jones RH, Guo D, Lister A (2005) Regeneration strategies, disturbance and plant interactions as organizers of vegetation spatial patterns in a pine forest. Landscape Ecol 20:971-987

Niinemets Ü (1997) Role of foliar nitrogen in light harvesting and shade tolerance of four temperate deciduous woody species. Funct Ecol 11:518-531

Nordell KO, Karlsson PS (1995) Resorption of nitrogen and dry matter prior to leaf abscission: variation among individuals, sites and years in the mountain birch. Funct Ecol 9:326-333

Poorter H, Niinemets U, Poorter L, Wright IJ, Villar R (2009) Causes and consequences of variation in leaf mass per area (LMA): a meta-analysis. New Phytol 182:565-588

R Development Core Team (2008) R: a language and environment for statistical computing. R Foundation for Statistical Computing, Vienna

Ribeiro PJ Jr, Diggle PJ (2001) GeoR: a package for geostatistical analysis. R News 1:15-18

Rich PM (1990) Characterizing plant canopies with hemispherical photographs. Rem Sens Rev 5:13-29

Robertson GP, Crum JR, Ellis BG (1993) The spatial variability of soil resources following long-term disturbance. Oecologia 96:451-456

Robertson GP, Klingensmith KM, Klug MJ, Paul EA, Crum JR, Ellis BG (1997) Soil resources, microbial activity, and primary production across an agricultural ecosystem. Ecol Appl 7:158-170
Rodríguez A, Durán J, Fernández-Palacios JM, Gallardo A (2009) Wildfire changes the spatial pattern of soil nutrient availability in Pinus canariensis forests. Ann For Sci 66:210

Rossi RE, Mulla DJ, Journel AG, Franz EH (1992) Geostatistical tools for modelling and interpreting ecological spatial dependence. Ecol Monogr 62:277-314

Ryel RJ, Caldwell MM, Manwaring JH (1996) Temporal dynamics of soil spatial heterogeneity in sage-brush-wheatgrass steppe during a growing season. Plant Soil 184:99-309

Schlesinger WH, Raikes JA, Hartley AE, Cross AF (1996) On the spatial pattern of soil nutrients in desert ecosystems. Ecology 77:364-374

Sims GK, Ellsworth TR, Mulvaney RL (1995) Microscale determination of inorganic nitrogen in water and soil extracts. Commun Soil Sci Plant Anal 26:303-316

Thomas H, Stoddart JL (1980) Leaf senescence. Annu Rev Plant Physiol 31:83-111

Walinga I, van der Lee JJ, Houba VJG, van Vark W, Novozamsky I (1995) Plant analysis manual. Kluwers, Dordrecht, p 253

Wang L, Mou PP, Jones RH (2006) Nutrient foraging via physiological and morphological plasticity in three plant species. Can J For Res 36:164-173

Wang L, Mou PP, Huang J, Wang J (2007) Spatial variation of nitrogen availability in a subtropical evergreen broadleaved forest of southwestern China. Plant Soil 295:137-150 